\title{
Erratum to: Crystal structures of GI.8 Boxer virus $P$ dimers in complex with HBGAs, a novel evolutionary path selected by the Lewis epitope
}

\author{
Ning Hao ${ }^{1,2}$, Yutao Chen ${ }^{1}$, Ming Xia ${ }^{3}$, Ming Tan ${ }^{3,4}$, Wu Liu ${ }^{1}$, \\ Xiaotao Guan', Xi Jiang ${ }^{3,4 \bowtie}$, Xuemei Li ${ }^{1}{ }^{1}$, Zihe Rao ${ }^{1}$ \\ ${ }^{1}$ National Laboratory of Biomacromolecules, Institute of Biophysics, Chinese Academy of Sciences, Beijing, 100101, China \\ ${ }^{2}$ University of Chinese Academy of Sciences, Beijing 100049, China \\ ${ }^{3}$ Division of Infectious Diseases, Cincinnati Children's Hospital Medical Center, Cincinnati, OH 45229, USA \\ ${ }^{4}$ University of Cincinnati College of Medicine, Cincinnati, OH 45267, USA \\ $\bowtie$ Correspondence: Jason.jiang@cchmc.org (X. Jiang), lixm@sun5.ibp.ac.cn (X. Li)
}

\section{ERRATUM TO: PROTEIN CELL 2015, 6(2):101-116 DOI 10.1007/S13238-014-0126-0}

In the original publication of the article, the contents in Acknowledgements section are published incomplete. The updated contents in Acknowledgements section is provided in this erratum.

Acknowledgements The research described in this article was supported by the National Basic Research Program (973 Program) (Nos. 2011CB910304 and 2011CB915501), the External Cooperation Program of the Chinese Academy of Sciences (Grant No. GJHZ1405), and the National Natural Science Foundation of China (Grant Nos. 31400639 and 31170702). The research of
Xi Jiang and Ming Tan's labs is supported by the US National Institute of Health (R01 Al089634/P01 HD13021 to X.J. and R21 AI092434/NCRR 8UL1TR000077-04 to M.T.).

\section{OPEN ACCESS}

This article is distributed under the terms of the Creative Commons Attribution 4.0 International License (http://creativecommons.org/ licenses/by/4.0/), which permits unrestricted use, distribution, and reproduction in any medium, provided you give appropriate credit to the original author(s) and the source, provide a link to the Creative Commons license, and indicate if changes were made. 